\title{
Prospecção Tecnológica: um mapeamento da Propriedade Intelectual no Instituto Federal de Educação, Ciência e Tecnologia do Amazonas (2015-2019)
}

\author{
Technological Prospection: a mapping of Intellectual Property in the \\ Amazon Federal Institute for Education, Science and Technology \\ (2015-2019)
}

\author{
Emmille Arruda Diogenes ${ }^{1}$ \\ Françoan Oliveira Dias ${ }^{1}$ \\ Layde Dayelle dos Santos Queiroz ${ }^{1}$ \\ Fabiana Lucena Oliveira ${ }^{2}$ \\ ${ }^{1}$ Universidade Federal do Amazonas, Manaus, AM, Brasil \\ ${ }^{2}$ Universidade do Estado do Amazonas, Manaus, AM, Brasil
}

\begin{abstract}
Resumo
O Instituto Federal de Educação, Ciência e Tecnologia do Amazonas (IFAM), atendendo à Lei n. 10.973/2004, Lei da Inovação, criou o Núcleo de Inovação Tecnológica (NIT), órgão vinculado à Pró-Reitoria de Pesquisa, PósGraduação e Inovação Tecnológica (PPGIT). O objetivo deste estudo é analisar a atuação do IFAM com relação ao desenvolvimento da Propriedade Intelectual no período de 2015 a 2019. Quanto à metodologia, utilizou-se o estudo de caso, sendo que, para atingir os objetivos da pesquisa, foram realizadas buscas bibliográficas e documentais. Os resultados apontam que o IFAM realizou no período de 2015 a 2019 o quantitativo de 25 registros e/ou depósitos junto ao INPI, sendo 2 marcas, 18 patentes e 5 programas de computador. Este estudo identifica as áreas que necessitam de maior atenção e investimento em processos inovativos por meio de um mapeamento da Propriedade Intelectual do IFAM a partir da criação do seu NIT.
\end{abstract}

Palavras-chave: Prospecção Tecnológica. Propriedade Intelectual. IFAM.

\begin{abstract}
The Federal Institute of Education, Science and Technology of Amazonas (IFAM), in compliance with Law n. 10,973/2004, Law of Innovation, created the Technological Innovation Nucleus (NIT), a body linked to the Dean of Research, Post- Graduation and Technological Innovation (PPGIT). The objective of this study was to analyze the role of IFAM in relation to the development of intellectual property in the period from 2015 to 2019 . As for the methodology, it was carried out through a case study, and to achieve the research objectives, bibliographic and documentary searches. The results indicate that IFAM carried out in the period from 2015 to 2019, the amount of 25 registrations and / or deposits with the INPI, being 2 brands, 18 patents and 5 computer programs. This study identifies areas that need more attention and investment in innovative processes, through a mapping of IFAM's intellectual property from the creation of its NIT.
\end{abstract}

Keywords: Technological Prospecting. Intellectual Property. IFAM.

Área Tecnológica: Gestão e Negócios. 


\section{Introdução}

Os Institutos Federais de Educação, Ciência e Tecnologia, criados em 29 de dezembro de 2008, por meio da sanção do Decreto Federal n. 11.892, surgiram com uma proposta de expansão do ensino pelo país, promovendo-o nos níveis básico, técnico e tecnológico, incluindo programas de formação e de qualificação de trabalhadores, licenciaturas e cursos de pós-graduação lato sensu e stricto sensu.

Nesse período, as Escolas Federais, que já estavam instaladas no Estado do Amazonas, como o Centro Federal de Educação Tecnológica do Amazonas (CEFET/AM), a Escola Agrotécnica Federal de Manaus e a Escola Agrotécnica Federal de São Gabriel da Cachoeira, passaram a integrar o IFAM, uma Instituição de ensino que já totaliza 15 campi no Estado (NUNES DE MELLO, 2009).

A partir da Figura 1 é possível visualizar a linha histórica que antecedeu a criação do IFAM.

Figura 1 - Trajetória do IFAM no Amazonas

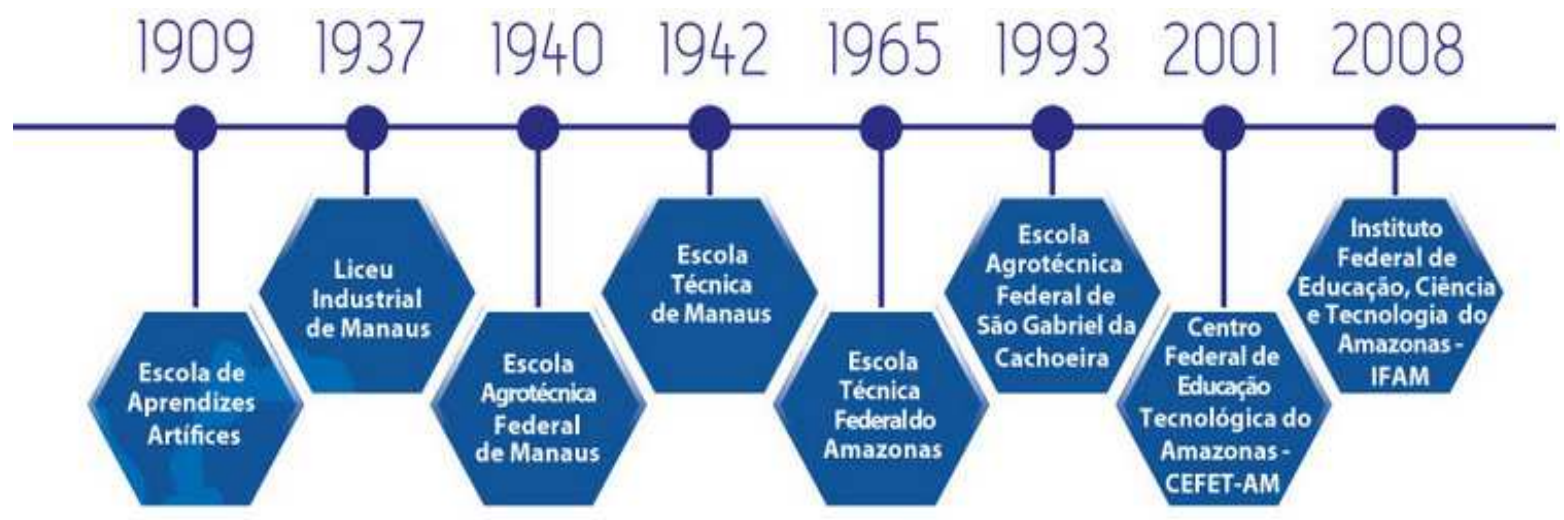

Fonte: Nunes de Mello (2009)

Com o decorrer dos anos, o IFAM passou a oferecer ensino tecnológico nas modalidades técnico subsequente, técnico integrado ao nível médio (regular e Proeja), graduação e pós-graduação em diversos eixos tecnológicos e áreas de conhecimento, possibilitando a criação de produtos intelectuais como marcas, patentes, programas de computador, entre outras criações do intelecto humano provenientes das atividades de ensino, pesquisa e extensão nas quais participam os discentes, docentes e demais servidores.

A propriedade intelectual é definida pela Organização Mundial da Propriedade Intelectual (OMPI) como um conjunto de direitos provenientes das criações do intelecto humano que se divide em direito autoral, propriedade industrial e proteção sui generis.

Para melhor definir, o Direito Autoral abrange o direito do autor, os direitos conexos e os programas de computador, já a Propriedade Industrial inclui marca, patente, desenho industrial, indicação geográfica, segredo industrial e repressão à concorrência desleal. A Proteção Sui Generis engloba topografia de circuito integrado, cultivar e conhecimento tradicional.

Considerando o rol de cursos que o IFAM compreende em seu eixos tecnológicos e áreas de conhecimento, que podem gerar produtos e serviços passíveis de serem resguardados nas proteções legais já mencionadas, mapear sua propriedade intelectual com vistas a quantificar os 
registros e/ou depósitos efetuados junto ao INPI, identificando os eixos e áreas de conhecimento mais atuantes nessa matéria são de relevância significativa, haja vista os benefícios que podem ser extraídos dessa proteção.

Esse mapeamento, realizado por meio de prospecção tecnológica, que, segundo Santana, Lima e Mourão (2004), tem como objetivo agregar valor às informações do presente, de forma a subsidiar tomadas de decisões frente às oportunidades e às necessidades futuras, contribui para os avanços tecnológicos, os benefícios pecuniários com transferência de tecnologias e para a criação de metas que permitam a continuidade das ações até aqui realizadas.

Estudos semelhantes a este foram realizados com diferentes enfoques, um foi produzido por Menezes et al. (2015), com abrangência nacional, considerando todos os IFs, outro foi feito por Araújo et al. (2018), a fim de mapear a propriedade intelectual dos IFs no Nordeste e ainda um estudo mais recente, que intenta esboçar um cenário entre a relação dos recursos aplicados em pesquisas tecnológicas e a evolução de depósitos e registros de propriedade intelectual, considerando o recorte temporal de 2014-2018 na Universidade Federal do Amazonas, de autoria de Oliveira et al. (2020). Dessa forma, a presente pesquisa está voltada apenas para o levantamento da Propriedade Intelectual no âmbito do IFAM, de forma a conhecer as particularidades desse Instituto.

A responsabilidade acerca do gerenciamento dos ativos intangíveis no IFAM está relacionada ao Núcleo de Inovação Tecnológica (NIT), tendo em vista o atendimento dos preceitos da Lei n. 10.973/2004 (Lei da Inovação), cuja vinculação está associada à Pró-Reitoria de Pesquisa, Pós-Graduação e Inovação Tecnológica (PPGIT).

No contexto estudado, o NIT se articula estrategicamente para promover a interação entre a pesquisa tecnológica realizada e as demandas das empresas existentes no mercado, além de validar tecnologias inovadoras que contribuam para o desenvolvimento da região na qual o IFAM está inserido.

Estabeleceu-se como objetivo geral desta pesquisa analisar a atuação do Instituto Federal de Educação, Ciência e Tecnologia do Amazonas (IFAM) com relação ao desenvolvimento da Propriedade Intelectual no período de 2015 a 2019, para isso, foram estabelecidos dois objetivos específicos, a saber: quantificar, no período supramencionado, os pedidos de registro e depósitos de propriedade intelectual realizados junto ao Instituto Nacional da Propriedade Industrial (INPI) e identificar os eixos tecnológicos e as áreas de conhecimento mais atuantes no IFAM que desenvolvem Propriedade Intelectual.

A realização da pesquisa justifica-se pela necessidade de prospectar informações que permitissem conhecer quais as áreas de atuação com maior e menor impacto, no que diz respeito à propriedade intelectual no âmbito do IFAM, de forma a fundamentar ações que fomentem os processos inovativos e, consequentemente, a representatividade do IFAM no cenário inovativo, por meio de depósitos e de registros de ativos intangíveis.

A importância deste estudo perpassa, então, pela publicização de dados relevantes à Instituição, ao mercado e à comunidade, haja vista que a prospecção dos bens imateriais do IFAM será realizada e poderá subsidiar ações que fundamentem a tomada de decisão por parte dos indivíduos que atuam direta ou indiretamente nos processos de inovação, possibilitando o planejamento de ações que fortaleçam a geração de Propriedade Intelectual na Instituição. 


\section{Metodologia}

A presente pesquisa caracteriza-se como quali-quantitativa, mediante um estudo de caso acerca da propriedade intelectual no IFAM, verificando o quantitativo de solicitações de registro e/ou depósito de Propriedade Intelectual, tendo em vista o incentivo à inovação e à pesquisa científica e tecnológica no ambiente produtivo por meio da criação de NITs nos Institutos Federais, desse modo, para atingir os objetivos do estudo, realizou-se buscas bibliográficas e documentais acerca da temática.

No que se refere à pesquisa bibliográfica, utilizou-se o Portal OasisBr, base de dados de acesso aberto e gratuito que recupera a produção intelectual de instituições de ensino e pesquisa no Brasil e em Portugal e o Portal de Periódicos da Coordenação de Aperfeiçoamento de Pessoal de Nível Superior (CAPES), que oferece o acesso a bases de dados internacionais.

Com relação à pesquisa documental, foi realizada no dia 29 de julho de 2019 por meio do Sistema Eletrônico do Serviço de Informação ao Cidadão (e-SIC) com o registro de pedido direcionado ao IFAM, gerando o protocolo 23480016729201966, a fim de solicitar o detalhamento de quantos depósitos de Propriedade Intelectual do Instituto estão em análise junto ao INPI, sendo o e-mail a forma de recebimento de tais informações.

Outro momento da pesquisa documental se deu mediante a consulta gratuita por meio da Internet no sistema Busca Web da base de dados do INPI, no qual foi possível localizar os depósitos realizados pelo IFAM, no período de 2015 a 2019, identificando, assim, na busca, as solicitações de registro para marcas, patentes e programas de computador.

Para Santos et al. (2004), a metodologia de prospecção busca compreender o futuro com o intuito de permitir a formulação de ações no presente. Este estudo prospectivo busca agregar valor às informações do presente, transformando-as em conhecimento para a construção de estratégias futuras para subsidiar a tomada de decisão. De posse dessas informações, analisou-se os dados extraídos, que serão apresentados nos resultados a seguir, considerando o tipo de propriedade intelectual e o eixo, ou área, ao qual está vinculado.

\section{Resultados e Discussão}

O Instituto Federal de Educação, Ciência e Tecnologia do Amazonas (IFAM), atendendo aos preceitos da Lei n. 10.973, de 2 de dezembro de 2004, intitulada também como Lei da Inovação, criou o NIT, órgão vinculado à Pró-Reitoria de Pesquisa, Pós-Graduação e Inovação Tecnológica (PPGIT). Cabe destacar que o NIT foi criado pela Portaria n. 1.127-GR/IFAM, de 28 de dezembro de 2010, com a função de gerir a política de inovação, promovendo e disseminando a cultura da Propriedade Intelectual no âmbito do IFAM.

Desse modo, o NIT deve criar oportunidades de integração da pesquisa tecnológica com as demandas das empresas e/ou validar tecnologias inovadoras de forma a aliar os esforços de coordenação do desenvolvimento conjunto para a região e para o país, conforme salienta Barbosa et al. (2019), ao afirmarem que a gestão da propriedade intelectual deve transformar 
o conhecimento gerado nas instituições em riquezas que desenvolvam também o País, trazendo retorno do investimento para melhorar suas práticas de pesquisa, desenvolvimento e inovação.

Como finalidades, o NIT/IFAM deverá: (I) interagir com os diversos setores do IFAM para criação e gestão de uma política institucional de inovação; (II) obter e gerir recursos orçamentários e financeiros advindos de instituições de fomento e das atividades proporcionadas pela Lei da Inovação; (III) proporcionar capacitação dos atores institucionais na gestão da inovação tecnológica, propriedade intelectual, transferência de tecnologia e na proteção intelectual; e (IV) estimular o setor empresarial a participar de projetos conjuntos de capacitação tecnológica e resoluções de demandas de inovação (IFAM, 2014a).

Outro ponto que deve ser observado é que ao NIT/IFAM compete gerir os aspectos relacionados à propriedade, à transferência e à gestão dos direitos de propriedade industrial, o direito de proteção a cultivares e as normas e procedimentos relativos ao registro de programas de computador e de direitos autorais, inerentes ou vinculados à criação ou à produção científica do IFAM. Pohlmann et al. (2018) reforçam a ideia de que a capacitação dos profissionais dos NITs é fundamental para a efetivação do gerenciamento de projetos complexos, bem como adequar os aspectos da transferência de tecnologia sob a dinâmica das necessidades do mercado.

De igual modo, torna-se também essencial a capacitação de todos os inventores do IFAM para que tenham ciência dos ativos intangíveis passíveis de proteção e saibam da importância em comunicar ao NIT as invenções desenvolvidas no âmbito da Instituição, além de se comprometerem em defender os interesses do Instituto, em termos da proteção intelectual, garantindo confidencialidade e sigilo sobre as invenções correspondentes.

De acordo com a Resolução n. 034-CONSUP/IFAM, de 22 de setembro de 2014, que aprova o Regimento do NIT do IFAM, qualquer criação ou inovação resultante de atividades desenvolvidas no âmbito do IFAM ou que decorram da aplicação de recursos humanos, orçamentários, dados, meios, informações e equipamentos do Instituto e/ou realizados durante o horário de trabalho, independentemente da natureza do vínculo entre esta e o inventor, estão sujeitos à proteção da propriedade intelectual (IFAM, 2014b).

Nesse cenário, o Plano de Desenvolvimento Institucional (PDI) 2014-2018 do IFAM traz como meta difundir a cultura de inovação tecnológica e da propriedade intelectual em todos os campi, tendo como indicador o número de eventos promovidos sobre o tema.

Entre as ações do PDI 2014-2018 (2014c) para fortalecimento e concretização da propriedade intelectual no Instituto, previu-se até 2018 o cumprimento das seguintes etapas: (I) realizar eventos objetivando a difusão da cultura de inovação tecnológica e da propriedade intelectual; (II) consolidar o NIT; (III) criar a infraestrutura física necessária para consolidação do NIT; e (IV) pleitear junto à Reitoria o efetivo necessário para a composição da equipe gestora do NIT.

Sendo assim, o NIT em 2015 realizou seus primeiros depósitos de pedido de patente junto ao INPI, sendo um do Campus São Gabriel da Cachoeira e um do Campus Manaus Centro. Outro ponto de destaque refere-se aos depósitos e/ou registros realizados pelo IFAM junto ao INPI no período de 2015 a 2019, totalizando duas marcas (Tabela 1), 18 patentes (Tabela 2) e cinco programas de computador (Tabela 3), considerando que o Instituto possui 15 campi e a Reitoria, conforme mostra o detalhamento a seguir. 
Tabela 1 - Registros de marcas realizados pelo IFAM junto ao INPI

\begin{tabular}{|c|c|c|c|c|c|c|}
\hline Processo & MaRCA & SituAÇÃo & APRESENTAÇÃo & Natureza & Apostila & RPI \\
\hline 905974727 & $\begin{array}{l}\text { Instituto } \\
\text { Federal } \\
\text { Amazonas }\end{array}$ & $\begin{array}{c}\text { Pedido } \\
\text { definitivamente } \\
\text { arquivado }\end{array}$ & Mista & De serviço & $\begin{array}{l}\text { Sem direito ao uso } \\
\text { exclusivo da expressão } \\
\text { "INSTITUTO } \\
\text { FEDERAL" }\end{array}$ & 2.369 \\
\hline 911985476 & $\begin{array}{c}\text { AYTY } \\
\text { Incubadora } \\
\text { de } \\
\text { Empresas } \\
\text { do IFAM }\end{array}$ & $\begin{array}{l}\text { Aguardando } \\
\text { apresentação } \\
\text { e exame de } \\
\text { recurso contra o } \\
\text { indeferimento }\end{array}$ & Mista & De serviço & Não se aplica & 2.502 \\
\hline
\end{tabular}

Fonte: Elaborada pelos autores deste artigo (2019)

Em relação aos registros de marca realizados pelo IFAM junto ao INPI, vide Tabela 1, percebe-se que no decorrer do período pesquisado, apenas duas solicitações de registros de marca ocorreram, sendo que o sinal distintivo do próprio Instituto (Processo n. 905974727) foi arquivado definitivamente por falta de pagamento de concessão. Em relação à marca da Incubadora de Empresas (Processo n. 911985476) foi indeferida por reproduzir ou imitar registros de terceiros, podendo inferir nesta última a necessidade de maior cautela no que diz respeito ao estado da técnica antes que ocorresse o depósito.

Tabela 2 - Depósitos de patentes realizados pelo IFAM junto ao INPI

\begin{tabular}{|c|c|c|c|c|c|c|c|}
\hline PEDIDo & DePósito & PublicaÇÃo & ConCESSÃo & Título & Depositante & INVENTOR & RPI \\
\hline BR1020150316135A2 & $17 / 12 / 2015$ & $20 / 06 / 2017$ & - & $\begin{array}{c}\text { Coletor } \\
\text { graduado } \\
\text { articulado } \\
\text { com apoio } \\
\text { basal de } \\
\text { amostra } \\
\text { indeformada } \\
\text { de solo }\end{array}$ & IFAM & $\begin{array}{c}\text { Bruno } \\
\text { Vinícius } \\
\text { Castro } \\
\text { Guimarães }\end{array}$ & 2.515 \\
\hline BR1020150316127 & $17 / 12 / 2015$ & - & - & - & IFAM & - & 2.424 \\
\hline BR1020160207967A2 & 09/09/2016 & $20 / 03 / 2018$ & - & $\begin{array}{c}\text { Balas de } \\
\text { polpa de } \\
\text { frutas e seu } \\
\text { processo de } \\
\text { produção }\end{array}$ & IFAM & $\begin{array}{l}\text { Lúcia } \\
\text { Schuch } \\
\text { Boeira }\end{array}$ & 2.463 \\
\hline BR1020160284570A2 & 02/12/2016 & $19 / 06 / 2018$ & - & $\begin{array}{l}\text { Hidrofólio } \\
\text { com perfil } \\
\text { variável }\end{array}$ & IFAM & $\begin{array}{l}\text { Flávio } \\
\text { Soares }\end{array}$ & 2.476 \\
\hline BR1020160285992A2 & 06/12/2016 & $17 / 07 / 2018$ & - & $\begin{array}{c}\text { Processo de } \\
\text { preparação e } \\
\text { conservação } \\
\text { do Tucupi } \\
\text { para o } \\
\text { consumo } \\
\text { humano }\end{array}$ & $\begin{array}{l}\text { IFAM/S. de } \\
\text { A. Viana } \\
\text { Fabricação } \\
\text { - ME }\end{array}$ & $\begin{array}{c}\text { Alves da } \\
\text { Silva/ } \\
\text { Rogete B. } \\
\text { Mendonça/ } \\
\text { Maria } \\
\text { Viana/ } \\
\text { José } \\
\text { Viana }\end{array}$ & 2.480 \\
\hline BR1020160287812A2 & 07/12/2016 & 19/06/2018 & - & $\begin{array}{c}\text { Bebida } \\
\text { alcoólica de } \\
\text { Rambutã e } \\
\text { seu processo } \\
\text { de produção }\end{array}$ & IFAM & $\begin{array}{l}\text { Lúcia } \\
\text { Schuch } \\
\text { Boeira }\end{array}$ & 2.476 \\
\hline
\end{tabular}




\begin{tabular}{|c|c|c|c|c|c|c|c|}
\hline Pedido & Depósito & Publicação & Concessão & Título & Depositante & INVENTOR & RPI \\
\hline BR1020160303877 & $22 / 12 / 2016$ & - & - & 更 & $\begin{array}{c}\text { IFAM/ } \\
\text { Cooperativa } \\
\text { Mista } \\
\text { Agroextrativista } \\
\text { Sardinha }\end{array}$ & 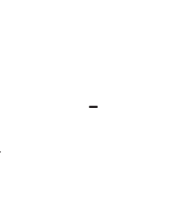 & 2.420 \\
\hline BR1020160305179A2 & $23 / 12 / 2016$ & $17 / 07 / 2018$ & - & $\begin{array}{c}\text { Bebida } \\
\text { alcoólica } \\
\text { obtida da } \\
\text { fermentação } \\
\text { da polpa de } \\
\text { Açaí e seu } \\
\text { processo de } \\
\text { produção }\end{array}$ & IFAM & $\begin{array}{l}\text { Lúcia } \\
\text { Boeira/ } \\
\text { Nicolle } \\
\text { Uchôa/ } \\
\text { Paulo } \\
\text { Freitas }\end{array}$ & 2.480 \\
\hline BR1020170137406A2 & $23 / 06 / 2017$ & $15 / 01 / 2019$ & - & $\begin{array}{c}\text { Processo } \\
\text { produtivo de } \\
\text { fabricação } \\
\text { de cascas } \\
\text { decorativas } \\
\text { de Castanha- } \\
\text { do-Brasil }\end{array}$ & $\begin{array}{c}\text { IFAM / } \\
\text { Cooperativa } \\
\text { Mista } \\
\text { Agroextrativista } \\
\text { Sardinha }\end{array}$ & $\begin{array}{l}\text { Ricardo } \\
\text { Aparecido } \\
\text { Bento }\end{array}$ & 2.506 \\
\hline BR1020170218350A2 & $10 / 10 / 2017$ & $30 / 04 / 2019$ & - & $\begin{array}{l}\text { Tinta a partir } \\
\text { de solos da } \\
\text { Amazônia e } \\
\text { seu processo } \\
\text { de produção }\end{array}$ & IFAM & $\begin{array}{l}\text { Fernanda } \\
\text { Villani/ } \\
\text { Gyovanni } \\
\text { Ribeiro }\end{array}$ & 2.521 \\
\hline BR1020170218015 & $10 / 10 / 2017$ & - & - & - & IFAM & - & 2.476 \\
\hline BR1020170219429A2 & $11 / 10 / 2017$ & 07/05/2019 & - & $\begin{array}{l}\text { Balas de } \\
\text { gelatina sem } \\
\text { açúcar e com } \\
\text { polpa de } \\
\text { frutas e seu } \\
\text { processo de } \\
\text { produção }\end{array}$ & IFAM & $\begin{array}{l}\text { Lúcia } \\
\text { Schuch } \\
\text { Boeira }\end{array}$ & 2.522 \\
\hline BR1020170224643A2 & $18 / 10 / 2017$ & 07/05/2019 & - & $\begin{array}{c}\text { Sistema e } \\
\text { processo de } \\
\text { cogeração } \\
\text { de energia } \\
\text { elétrica para } \\
\text { servidores em } \\
\text { ambiente de } \\
\text { datacenters }\end{array}$ & IFAM & $\begin{array}{l}\text { Fabiano } \\
\text { Stingelin } \\
\text { Cardoso }\end{array}$ & 2.522 \\
\hline BR1020170280462 & $22 / 12 / 2017$ & - & - & - & IFAM & $\begin{array}{c}\text { Dipeixe } \\
\text { Indústria e } \\
\text { Comercio } \\
\text { Ltda. }\end{array}$ & 2.473 \\
\hline BR1020180111639 & $30 / 05 / 2018$ & - & - & - & IFAM & $\begin{array}{l}\text { Caíque } \\
\text { da Silva }\end{array}$ & 2.501 \\
\hline BR1020180167928 & $16 / 08 / 2018$ & - & - & - & IFAM & - & 2.496 \\
\hline BR1020180763342 & $17 / 12 / 2018$ & - & - & - & IFAM & - & 2.506 \\
\hline BR1020190105429 & $23 / 05 / 2019$ & - & - & - & IFAM & $\begin{array}{l}\text { Caíque } \\
\text { da Silva }\end{array}$ & 2.533 \\
\hline
\end{tabular}

Fonte: Elaborada pelos autores deste artigo (2019) 
Com relação aos dados da Tabela 2, que trata sobre os depósitos de patentes realizados pelo IFAM junto ao INPI, percebe-se que, das 18 solicitações do período em questão, houve em 2015 o equivalente a 2 depósitos (11,12\%), 6 em 2016 (33,33\%), 9 em 2017 (50\%) e, até o primeiro semestre de 2019, 1 depósito (5,5\%).

No que concerne às publicações dos pedidos aceitos para tramitação normal do processo, até o presente momento já passaram do Exame Formal Preliminar, em conformidade com o prazo legal, o quantitativo de 10 depósitos ocorridos entre 2015 e 2017, sendo que os demais pedidos passam pelo processo de complementação da documentação ou ainda estão sendo analisados.

Cabe destacar que, na maioria das vezes, o IFAM será o depositante, mas poderá fazer em parceria com outras organizações. Já em relação aos inventores, em sua maioria, são docentes $e$ discentes da Instituição. Até o momento nenhum registro de patente foi concedido pelo INPI ao IFAM, considerando que o prazo de concessão poderá ser de até 10 anos no Brasil e no exterior de até três anos.

Tabela 3 - Depósitos de programas de computador realizados pelo IFAM junto ao INPI

\begin{tabular}{|c|c|c|c|c|c|c|c|}
\hline DEPÓSITO & LINGUAGEM & AplicAÇÃo & Programa & Título & TITULAR & Autor & RPI \\
\hline BR5120180004970 13/04/2018 & $\mathrm{C \#} / \mathrm{C}++$ & $\begin{array}{l}\mathrm{AD}-08 \text { / } \\
\mathrm{BL}-04 \text { / } \\
\text { ED-04 }\end{array}$ & GI-02 & $\begin{array}{l}\text { Micoteca } \\
\text { Digital }\end{array}$ & IFAM & $\begin{array}{c}\text { Hannah } \\
\text { Karoline } \\
\text { Andrade } \\
\text { Pinheiro/ larima } \\
\text { Naama Ferreira } \\
\text { Lopes/ Juliana } \\
\text { Mesquita Vidal } \\
\text { Martínez de } \\
\text { Lucena/ } \\
\text { Luiz Henrique } \\
\text { da Silveira Brito }\end{array}$ & 2.468 \\
\hline BR5120180008909 07/06/2018 & DELPHI & ED-03 & AP-03 & CI-Web & IFAM & $\begin{array}{c}\text { Iandra Maria } \\
\text { Weirich da Silva } \\
\text { Coelho/Miguel } \\
\text { Bonafe Barbosa }\end{array}$ & 2.476 \\
\hline BR5120180010652 28/06/2018 & $\begin{array}{l}\mathrm{C}++1 \\
\mathrm{JAVA}\end{array}$ & IN-02 & AP-01 & Kde Tu & IFAM & $\begin{array}{c}\text { Adson Fialho } \\
\text { Marques/ } \\
\text { Augusto Cesar } \\
\text { Alves Bacovis/ } \\
\text { Felipe Palma } \\
\text { de Oliveira } \\
\text { Cunha/Vinícius } \\
\text { Rocha Lima da } \\
\text { Silva/Vitor } \\
\text { Bremgartner } \\
\text { da Frota }\end{array}$ & 2.479 \\
\hline BR5120180524311 17/12/2018 & $\begin{array}{c}\text { HTML / } \\
\text { PYTHON }\end{array}$ & ED-01 & ET-02 & $\begin{array}{c}\text { Game } \\
\text { Alfa }\end{array}$ & IFAM & $\begin{array}{c}\text { Austonio } \\
\text { Queiroz dos } \\
\text { Santos/José } \\
\text { Anglada Rivera }\end{array}$ & 2.504 \\
\hline BR5120190013913 02/07/2019 & DELPHI & ED-03 & AP-03 & CI-Web & IFAM & $\begin{array}{c}\text { Iandra Maria } \\
\text { Weirich da Silva } \\
\text { Coelho/Miguel } \\
\text { Bonafe Barbosa }\end{array}$ & 2.531 \\
\hline
\end{tabular}

Fonte: Elaborada pelos autores deste artigo (2019) 
Quanto aos registros de programa de computador realizados pelo IFAM junto ao INPI, conforme mostra a descrição na Tabela 3, percebe-se um aumento significativo a partir de 2018, em que é possível identificar 4 registros nesse período e 1 em 2019 , cuja validade será de 50 anos contados a partir da $1^{\circ}$ de janeiro subsequente à data de publicação, em conformidade com o $§ 2^{\circ}$, art. $2^{\circ}$ da Lei 9.609 , de 19 de fevereiro de 1998. Desse modo, considera-se um ativo para o IFAM que poderá ter retorno financeiro para investimentos em propriedade intelectual no âmbito do Instituto.

Percebeu-se que os pedidos de registro de marca ou programa de computador, juntamente com o depósito de patente realizados pelo IFAM, no INPI, abrangem alguns eixos tecnológicos de nível médio e algumas áreas de conhecimento de nível superior. Quanto aos eixos tecnológicos, tem-se: Controle e Produção, Gestão e Negócio, Produção Cultural e Design, Produção Alimentar, Recursos Naturais, Produção Industrial, Controle e Processos Industriais, Ciências Agrárias e Ciências Biológicas.

Em relação às áreas de conhecimento, elas se direcionam as Ciências Exatas e da Terra, Ciências Biológicas, Engenharia e Ciências Agrárias, podendo se expandir para os demais eixos e áreas nos NITs dos campi. Por fim, destaca-se que todos os pedidos do IFAM tramitaram no mais estrito sigilo durante o período de 18 meses, até que seja publicado na Revista de Propriedade Industrial (RPI).

Salienta-se que conhecer as áreas mais atuantes em relação à PI pode ser um diferencial competitivo à Instituição, haja vista que mostra quais áreas devem receber maior atenção para que seu potencial inovativo comece a ser explorado, tratando as áreas que já possuem ativos protegidos e elaborando estratégias para manter ou aumentar a execução de atividades que impulsionem a geração de PI.

Em atenção aos eixos e áreas de conhecimento mais atuantes, é possível ter um contato mais próximo com os pesquisadores, alunos e docentes envolvidos ou que desejam se envolver em projetos que originem ativos passíveis de proteção, cujos benefícios estão amplamente relacionados ao retorno financeiro à Instituição por meio de transferência de tecnologia, a utilização desses ativos para solucionar problemas locais, nacionais ou globais, reconhecimento do pesquisador perante a comunidade científica e impulsionamento das parcerias existentes entre o IFAM e o terceiro setor.

Em um estudo realizado no período de 2006 a 2013, Menezes et al. (2015) afirmam que foram depositados um total de 87 patentes no INPI pelos Institutos Federais de Educação e indica que a maioria dos depósitos é oriunda dos IFs do Nordeste, o que é melhor detalhado por Araújo et. al. (2018), ao realizarem um estudo que mostrou o quantitativo de PI depositado nos IFs do Nordeste no recorte temporal de 2006 a 2016, chegando à conclusão de que, de acordo com a Classificação Internacional de Patentes, os depósitos dos Institutos Federais da Região Nordeste estão classificados, em sua maioria, na Série A (Necessidades Humanas), Série G (Física) e Série C (Química e Metalúrgica). Trazendo para a realidade do IFAM, os dados acerca dos depósitos de patentes apontam que, os que apresentam classificação estão na Série A, que trata de Necessidades Humanas.

Pereira, Costa e Pereira (2016), em um estudo com recorte temporal de 1979 a 2013, afirmam que a Região Norte apresenta $2 \%$ de patentes concedidas, porém os dados obtidos na 
presente pesquisa não são contemplados neste estudo, haja vista que os pedidos de registro ou depósito do IFAM são posteriores às datas contempladas pelos pesquisadores.

O conhecimento aportado neste estudo será capaz de subsidiar as ações do NIT do IFAM a fim de direcionar seu olhar sobre as áreas que ele mais tem protegido e sobre aquelas que ainda não desenvolvem inovação, ampliando a discussão e possível mobilização do corpo técnico-científico para atuar nas frentes que julgarem necessárias.

\section{Considerações Finais}

A partir dos resultados obtidos, percebe-se a relevante atuação do NIT no âmbito do IFAM no que diz respeito ao processo de proteção e prospecção dos seus ativos intangíveis, tanto no sentido academia-empresa quanto empresa-academia, porém, presume-se que alguns resultados de pesquisas, passíveis de registro ou depósito junto ao INPI, não se efetivem devido à falta de orientação em relação aos trâmites internos para a garantia da proteção e o desconhecimento sobre a possibilidade de proteção da criação oriunda do intelecto humano.

Dessa forma, tornar conhecido aos inventores do IFAM esses trâmites é fundamental para concretizar de fato a proteção dos resultados de pesquisas realizadas no âmbito do IFAM. Ressalta-se que antes de haver uma Política de Inovação no Instituto, já eram previstas no Plano de Desenvolvimento Institucional (PDI) 2014-2018 ações para difundir a cultura de inovação tecnológica e da propriedade intelectual em todos os campi.

Constatou-se também a necessidade de maior capacitação dos servidores do IFAM no sentido de conhecer a legislação pertinente, bem como a importância da aplicação da propriedade intelectual dentro da Administração Pública, além de incentivar as ações da incubadora de empresas do próprio Instituto.

Os resultados obtidos no corte de tempo selecionado mostram a atuação do NIT, em se tratando de depósitos e registros entre 2015 e 2019, em que a maior atividade ocorreu em 2017 , conforme demonstrado na pesquisa, totalizando duas marcas (Tabela 1), 18 patentes (Tabela 2) e cinco programas de computador (Tabela 3).

Conforme apresentado na Tabela 1, o Eixo Tecnológico de Produção Cultural e Design, do qual faz parte o curso de Tecnologia em Produção Publicitária, não possui marcas registradas junto ao INPI ou qualquer outro ativo intelectual proveniente de trabalhos de conclusão de curso ou outras atividades de ensino, pesquisa e extensão. Na Tabela 2, o Eixo tecnológico de Produção Alimentar se mostra atuante por meio do considerável número de depósitos de patentes realizado pelo Curso de Tecnologia de Alimentos. De acordo com as informações da Tabela 3, nota-se a existência de programas de computador criados por servidores para atender a uma demanda institucional e outros para atender a demandas sociais.

Atualmente, o índice de depósito de patentes é o mais alto em relação aos demais ativos intangíveis existentes na Instituição, seguido pelos registros de software e marcas, respectivamente. O NIT do IFAM mostra-se atuante, contudo, há a necessidade de uma maior divulgação para a comunidade acadêmica sobre a importância de proteger os bens intelectuais gerados no âmbito da Instituição.

Considerando a tradição histórica dos cursos voltados para as áreas de alimentos, ciências agrárias, engenharias e química no IFAM, o cenário de proteção da propriedade intelectual po- 
deria ser mais representativo partindo do potencial tecnológico inovador adquirido no ambiente acadêmico, sendo que, somente nos últimos anos, esse cenário começou a mudar.

Considerando a diversidade de áreas de conhecimento e eixos tecnológicos dos cursos que possui, o IFAM apresenta potencial para atuar nos diversos nichos abrangidos pela propriedade intelectual. Faz-se necessário despender maior atenção aos cursos de Medicina Veterinária, Tecnólogo em Agroecologia, Engenharia Mecânica, Engenharia Civil, Engenharia de Software, Mecatrônica, inclusive as Licenciaturas. Por fim, diante dos resultados alcançados nesta pesquisa, cabe apresentar algumas sugestões para novos estudos que possam abordar e complementar o desenvolvimento do tema. Sugere-se o mapeamento da propriedade intelectual em suas diversas tipologias no âmbito do IFAM para, assim, verificar as proteções cabíveis ao ativo.

\section{Perspectivas Futuras}

Sugere-se como pesquisa futura um novo estudo a fim de atualizar os dados referentes ao depósito ou registro de marcas, patentes e programas de computador do IFAM, de modo a suprir necessidades da comunidade, de forma que a inovação seja realizada a partir de demandas reais, subsidiando o apoio a ações de desenvolvimento tecnológico e a negociação de transferência de tecnologias. Sugere-se ainda a realização de novos estudos prospectivos em IFs para conhecer a situação e acompanhar a evolução dos depósitos e registros de PI em cada Instituição.

Por fim, os dados analisados nesta pesquisa tornam-se estratégicos no que diz respeito ao planejamento e à administração de recursos financeiros e orçamentários para alicerçar e contribuir para a evolução dos ativos intangíveis no IFAM, haja vista que isso torna conhecidas as áreas com mais ativos protegidos e aponta quais áreas podem ser melhor estimuladas.

\section{Referências}

ARAÚJO, L. O. et al. Mapeamento da propriedade industrial nos Institutos Federais de Educação no Nordeste. Cadernos de Prospecção, Salvador, v. 11, Edição Especial, p. 284-294, abr.-jun. 2018. Disponível em: file://C:/Users/patyc/Downloads/23078-108507-1-PB.pdf. Acesso em: 31 mar. 2020.

BARBOSA, A. M. A. et al. Um panorama do desempenho em inovação no Brasil e a busca por boas práticas de gestão na Transferência de Tecnologia (TT) nas instituições de Ciência e Tecnologia (ICT) do Brasil. Cadernos de Prospecção, Salvador, v. 12. n. 3. p. 504-522, 2019. Disponível em: https:// portalseer.ufba.br/index.php/nit/article/view/27256/17924. Acesso em: 31 mar. 2020.

BRASIL. Lei n. 9.609, de 19 de fevereiro de 1998. Dispõe sobre a proteção da propriedade intelectual de programa de computador, sua comercialização no País, e dá outras providências. Brasília: Presidência da República, 1998. Disponível em: https://bit.ly/2tjocSu. Acesso em: 14 ago. 2019.

IFAM - INSTITUTO FEDERAL DE EDUCAÇÃO, CIÊNCIA E TECNOLOGIA DO AMAZONAS. Núcleo de Inovação Tecnológica. Manaus: IFAM, 2014a. Disponível em: https://bit.ly/2N6bF0t. Acesso em: 14 ago. 2019. 
IFAM - INSTITUTO FEDERAL DE EDUCAÇÃO, CIÊNCIA E TECNOLOGIA DO AMAZONAS. Conselho Superior. Resolução n. 034 CONSUP/IFAM, de 22 de setembro de 2014. Dispõe sobre o Regimento do Núcleo de Inovação Tecnológica - (NIT) do Instituto Federal de Educação, Ciência e Tecnologia do Amazonas. Manaus: Conselho Superior, 2014b. Disponível em: http:// www2.ifam.edu.br/pro-reitorias/pesquisa-e-inovacao/arquivos-ppgi/Resoluon034AprovaoReg. doNcleodeInov.TecnolgicaNITdoIFAM.pdf. Acesso em: 31 mar. 2020.

IFAM - INSTITUTO FEDERAL DE EDUCAÇÃO, CIÊNCIA E TECNOLOGIA DO AMAZONAS. Plano de Desenvolvimento Institucional 2014-2018. Manaus: IFAM, 2014c. Disponível em: https://bit.ly/2P0eAKQ. Acesso em: 14 ago. 2019.

MENEZES, C. C. N. et al. Prospecção tecnológica no Brasil: um mapeamento da Propriedade Industrial nos Institutos Federais de Educação. Cadernos de Prospecção, Salvador, v. 8, n.1, p. 2128, jan.-mar. 2015. Disponível em: https://portalseer.ufba.br/index.php/nit/article/view/11587/pdf_85. Acesso em: 31 mar. 2020.

NUNES DE MELLO, M. S. de V. De Escola de Aprendizes Artífices a Instituto Federal de Educação, Ciência e Tecnologia do Amazonas: cem anos de história. Manaus: [s.n.], 2009.

OLIVEIRA, L. M. P. et al. A Política de Inovação e sua Aplicação na Universidade Federal do Amazonas. Cadernos de Prospecção, Salvador, v. 13, n. 1, p. 49-65, 2020. Disponível em: https:// portalseer.ufba.br/index.php/nit/article/view/32775. Acesso em: 31 mar. 2020.

PEREIRA, F. C.; COSTA, H. G.; PEREIRA, V. Estudo das patentes concedidas com a participação de universidades brasileiras. In: ENCONTRO NACIONAL DE ENGENHARIA DE PRODUÇÃO, 36., 2016, João Pessoa. Anais [...]. João Pessoa: ENEGEP, 2016. p. 1-16. Disponível em: https://www. researchgate.net/publication/311065587_ESTUDO_DAS_PATENTES_CONCEDIDA S_COM_A_ PARTICIPACAO_DE_UNIVERSIDADES_BRASILEIRAS Ācesso em: 20 mar. 2018.

POHLMANN, J. R. et al. Análise do processo de Transferência de Tecnologia de uma Universidade sob a ótica dos Sistemas Lean. Cadernos de Prospecção, Salvador, v. 11. n. 5. p. 1.239-1.255, 2018. Disponível em: https://bit.ly/3dIdnzW. Acesso em: 31 mar. 2020.

SANTANA, M. F. S.; LIMA, A. K. V. O.; MOURÃO, M. Avaliação prospectiva do açaí: análise através dos pedidos de patentes e referências bibliográficas. GEINTEC, São Cristóvão, v. 4, p. 437-452, 2014. Disponível em: encurtador.com.br/efwGZ. Acesso em: 31 mar. 2020.

SANTOS, M. M. et al. Prospecção de tecnologias de futuro: métodos, técnicas e abordagens.

Parcerias Estratégicas, Brasília, v. 9, n. 19, p. 189-229, 2004. Disponível em: http://seer.cgee.org. br/index.php/parcerias_estrategicas/article/view/253. Acesso em: 16 ago. de 2019.

WIPO - WORLD INTELLECTUAL PROPERTY ORGANIZATION. What is intellectual property? Genebra: WIPO, [2019]. Disponível em: https://bit.ly/2wwTJm1. Acesso em: 14 ago. 2019.

\section{Sobre os Autores}

\section{Emmille Arruda Diogenes}

E-mail: emmille.diogenes@gmail.com

Especialista em Gestão Pública e Legislação Urbana pela Universidade Candido Mendes em 2017.

Endereço profissional: Rua Carlos Antônio Sáles, s/n, Floresta, Umirim, CE. CEP: 62660-000. 


\section{Françoan Oliveira Dias}

E-mail: francoan.dias@gmail.com

Mestre em Gestão e Regulação de Recursos Hídricos pela Universidade do Estado do Amazonas em 2020.

Endereço profissional: Av. Carlos Drummond de Andrade, Bloco G, conj. Atílio Andreazza, n. 1.460, Japiim, Manaus, AM. CEP: 69077-730.

\section{Layde Dayelle dos Santos Queiroz}

E-mail: layde_queiroz@hotmail.com

Especialista em Gestão de Bibliotecas Escolares pela Unyleya em 2017.

Endereço profissional: Av. Sete de Setembro, n. 1.975, Centro, Manaus, AM. CEP: 69020-120.

\section{Fabiana Lucena Oliveira}

E-mail: flucenaoliveira@gmail.com

Doutora em Engenharia de Transportes pelo Instituto Alberto Luiz Coimbra de Pós-Graduação em Engenharia em 2009.

Endereço profissional: Av. Castelo Branco, até 1.005/1.006, Cachoeirinha, Manaus, AM. CEP: 69065-010. 